\title{
Mode of action of abatacept in rheumatoid arthritis patients having failed tumour necrosis factor blockade: a histological, gene expression and dynamic magnetic resonance imaging pilot study
}

\author{
M H Buch, ${ }^{1}$ D L Boyle, ${ }^{2}$ S Rosengren, ${ }^{2}$ B Saleem, ${ }^{1}$ R J Reece, ${ }^{1}$ L A Rhodes, ${ }^{3}$ \\ A Radjenovic, ${ }^{3}$ A English, ${ }^{1} \mathrm{H}$ Tang, ${ }^{4} \mathrm{G}$ Vratsanos, ${ }^{4} \mathrm{P} 0$ O'Connor, ${ }^{5} \mathrm{G} S$ Firestein, ${ }^{2} \mathrm{P}$ Emery
}

- A supplementary methods section is published online only at http://ard.bmi.com/content/ vol68/issue7

\section{${ }^{1}$ Academic Unit of}

Musculoskeletal Disease,

University of Leeds, Leeds, UK:

${ }^{2}$ Center for Innovative Therapy,

Biomarker Laboratory, University of California, San Diego,

California, USA; ${ }^{3}$ Academic Unit of Medical Physics, University of Leeds, Leeds, UK; ${ }^{4}$ BristolMyers Squibb, Princeton, New Jersey, USA; ${ }^{5}$ Department of Radiology, Leeds General Infirmary, Leeds, UK

Correspondence to: Professor P Emery, Leeds Teaching Hospitals NHS Trust, Academic Unit of

Musculoskeletal Disease Second Floor, Chapel Allerton Hospital, Chapeltown Road, Leeds LS7 4SA, UK: p.emery@leeds.ac.uk

Accepted 3 August 2008 Published Online First 4 September 2008

\section{UNLOCKA}

This paper is freely available online under the BMJ Journals unlocked scheme, see http:// ard.bmj.com/info/unlocked.dtl

\section{ABSTRACT}

Objectives: Abatacept is the only agent currently approved to treat rheumatoid arthritis (RA) that targets the co-stimulatory signal required for full T-cell activation. No studies have been conducted on its effect on the synovium, the primary site of pathology. The aim of this study was to determine the synovial effect of abatacept in patients with RA and an inadequate response to tumour necrosis factor alpha (TNF $\alpha$ ) blocking therapy.

Methods: This first mechanistic study incorporated both dynamic contrast-enhanced (DCE) magnetic resonance imaging (MRI) and arthroscopy-acquired synovial biopsies before and 16 weeks after therapy, providing tissue for immunohistochemistry and quantitative real-time PCR analyses.

Results: Sixteen patients (13 women) were studied; all had previously failed TNFa-blocking therapy. Fifteen patients completed the study. Synovial biopsies showed a small reduction in cellular content, which was significant only for B cells. The quantitative PCR showed a reduction in expression for most inflammatory genes (Wald statistic of $p<0.01$ indicating a significant treatment effect), with particular reduction in IFN $\gamma$ of $-52 \%(95 \% \mathrm{Cl}-73$ to $-15, p<0.05)$; this correlated well with MRI improvements. In addition, favourable changes in the osteoprotegerin and receptor activator of nuclear factor kappa B levels were noted. DCE-MRI showed a reduction of 15$40 \%$ in MRI parameters.

Conclusion: These results indicate that abatacept reduces the inflammatory status of the synovium without disrupting cellular homeostasis. The reductions in gene expression influence bone positively and suggest a basis for the recently demonstrated radiological improvements that have been seen with abatacept treatment in patients with RA.

Understanding of disease pathogenesis in rheumatoid arthritis (RA) has led to novel approaches in targeted drug development. Despite the demonstrated success of tumour necrosis factor (TNF) antagonists, up to $50 \%$ of patients have an inadequate response to TNF blockade therapy. ${ }^{1-4}$ This observation has fuelled the search for alternative targeted approaches.

Abatacept is a recombinant fusion protein comprising the extracellular domain of human cytotoxic T-lymphocyte antigen 4 and a fragment of the $\mathrm{Fc}$ domain of human IgG1. It acts by competing with CD28 for binding to CD80/CD86, modulating the second co-stimulatory signal required for full $\mathrm{T}$-cell activation. ${ }^{56}$
Abatacept has demonstrated benefits in patients with RA and an inadequate response to methotrexate $^{7}$ that are comparable to those observed in studies of TNF blockade, with efficacy also confirmed in the particularly resistant group of patients who have failed TNF blockade therapy. ${ }^{8}$

There is limited information on the impact of costimulation modulation on the synovium. The objective of this first mechanistic study was to determine the synovial effect of abatacept in a TNF antagonist-resistant group of patients. A novel and validated method of gene expression analysis was employed in combination with immunohistochemistry to evaluate the changes in synovial pro-inflammatory cytokine gene expression and cell populations, respectively, with evaluation of magnetic resonance imaging (MRI) changes before and after abatacept therapy.

\section{PATIENTS AND METHODS}

This was a collaborative, prospective, open-label study between the Academic Unit of Musculoskeletal Disease, University of Leeds and the Center for Innovative Therapy, University of California San Diego, sponsored by Bristol-Myers Squibb. Leeds research ethics committee approval was obtained before study initiation. The study was conducted in accordance with the ethical principles of the Declaration of Helsinki. All patients provided written informed consent. The US Food and Drug Administration registration number for this clinical trial is NCT00162201.

\section{Patients}

All patients were recruited from the Leeds Biologic Clinic, had a diagnosis of RA, as defined by the 1987 American College of Rheumatology criteria ${ }^{9}$ and had currently or previously failed a TNFblocking therapy. TNF blockade inefficacy was defined as failure of the disease activity score 28 (DAS28) to improve by 1.2 or more after 3 months of therapy as per British Society of Rheumatology guidelines. ${ }^{10}$ Patients were also required to have evidence of active disease defined by a DAS28 of more than 5.1 and a tender and swollen knee joint identified as a target joint for arthroscopy.

Exclusion criteria included: patients with evidence of active tuberculosis; previous tuberculosis; chest $x$ ray granuloma or tuberculosis exposure with a mantoux reading of $5 \mathrm{~mm}$ or greater if no 
previous history of bacillus Calmette-Guérin (BCG), or $10 \mathrm{~mm}$ or more if patients had previously received BCG. Pregnant or lactating women; patients with a history of septic arthritis in the last year and those with severe co-morbidity, including a history of recurrent infections, were also excluded.

\section{Concomitant therapy}

Background disease-modifying antirheumatic drugs for at least 3 months and at stable doses for at least 28 days before the first dose of abatacept were required (methotrexate (subcutaneous/ intramuscular), hydroxychloroquine and sulphasalasine permitted). Low-dose stable corticosteroids and/or stable nonsteroidal anti-inflammatory drugs were allowed. Patients who were currently receiving TNF-blocking agents were required to have discontinued etanercept and adalimumab for at least 28 days or infliximab for at least 60 days before day 1 .

\section{Study schedule}

Following successful screening at a maximum of day -28 , patients underwent clinical evaluation to confirm the DAS28 (erythrocyte sedimentation rate; ESR) score and also dynamic contrast-enhanced (DCE) MRI and arthroscopy of the target knee joint between days -6 and 0 . Arthroscopy was performed within 2 days of the DCE-MRI scan. All patients received abatacept by intravenous infusion according to baseline weight (<60 kg received $500 \mathrm{mg}, 60-100 \mathrm{~kg}$ inclusive received $750 \mathrm{mg}$ and $>100 \mathrm{~kg}$ received $1000 \mathrm{mg}$ ). Six infusions were administered, each over approximately 30 minutes on days $1,15,29,57$, 85 and 113.

Clinical assessments were repeated at day 57. Following completion of treatment, patients had further clinical evaluation for DAS28 (ESR) calculation, DCE-MRI and arthroscopy of the target knee joint between days 120 and 127. Below is a summary of methods (complete details included in the supplementary information published online only).

\section{Arthroscopy and synovial biopsy}

Patients underwent medical arthroscopy of a swollen knee joint before commencing abatacept therapy and after completion of treatment as described above with multiple synovial biopsies obtained. The arthroscopist (RJR) was blinded to the clinical response.

Table 1 Baseline patient demographics and disease characteristics

\begin{tabular}{lc}
\hline & $\begin{array}{c}\text { All patients } \\
(\mathbf{n}=16)\end{array}$ \\
\hline Patient demographics & \\
Age, years & $53.8(11.5)$ \\
Gender, \% female & 81.0 \\
Race, \% white & 94.0 \\
Weight, kg & $72.6(17.3)$ \\
Disease characteristics & \\
Rheumatoid factor positive* (\%) & 75.0 \\
CRP, mg/l & $5.8(5.6)$ \\
ESR, mm/h & $58.9(27.0)$ \\
VAS, 100 mm & $66.5(15.5)$ \\
Baseline DAS28 & $7.1(0.9)$ \\
Baseline tender joint count, /28 & $14.0(6.0)$ \\
Baseline swollen joint count, /28 & $19.2(7.2)$
\end{tabular}

Data are presented as means (SD) unless otherwise stated; ${ }^{*} n=15$; CRP, C-reactive protein; DAS28, disease activity score 28; ESR, erythrocyte sedimentation rate; VAS, visual analogue scale for patient global assessment of disease activity.

\section{Immunohistochemistry}

The cell types analysed by immunohistochemistry included: lining layer (LL) and sub-lining layer (SL) CD3+, CD154 (CD40L)+ and CD4+ $\mathrm{T}$ cells; CD80+ and CD86+ antigen presenting cells; CD20+ and CD79+ B cells; CD55+ synovial fibroblasts; CD54+ cells (intercellular adhesion molecules); CD68+ synovial macrophages; and CD11b+ neutrophils, macrophages and dendritic cells. A standard staining procedure using ChemMate (DakoCytomation, Glostrup, Denmark) was used. 3,3'-Diaminobenzidine was used to develop colour.

\section{Microscopic analysis}

Sections were randomly analysed and the histological features scored in blinded fashion (by MHB and $\mathrm{AE}$ ) using a validated semiquantitative scoring system. ${ }^{11}$

\section{Quantitative real-time PCR}

Methods for messenger RNA analysis have previously been described. ${ }^{12}$ Pooled biopsy fragments were used to synthesise complementary DNA. The TaqMan PCR method was undertaken for gene expression analysis of IL-1, IL-6, matrix metalloproteinase (MMP) 1, MMP-3 and IFN $\gamma$. Results were expressed in relative expression units. ${ }^{12}$

\section{DCE-MRI and image processing}

Dynamic (during and after contrast agent gadolinium diethylenetriaminepentaacetic acid) MRI of the knee was performed using a Philips 1.5T Gyroscan ACS-NT whole-body scanner (Philips Medical Systems, Best, The Netherlands) with a Philips quadrature knee coil.

\section{Image analysis}

Commercial software (Analyze, Mayo Clinic, New York, USA) and software developed in-house ${ }^{13}$ were used to calculate values for the maximal enhancement (ME) and the initial rate of contrast enhancement (IRE) on a pixel-by-pixel basis. ME and IRE provide an assessment of the synovial microcirculation.

\section{Measurements of MRI parameters}

Global

$M E$ and IRE were measured in regions of interest (ROI) defining the extent of the synovitis using the image analysis software at a level of 10 pixels below the tibial plateau to the top of the suprapatellar pouch (SPP) (regions of SPP, cartilage-pannus junction and a distant site in the SPP). ${ }^{14}$ Data analysis was performed by a blinded investigator (LAR).

\section{Statistical analysis}

\section{Immunohistochemistry}

Median baseline semiquantitative scores for cell populations were calculated for responders, non-responders and the overall patient population. The Wilcoxon signed rank test was applied to determine significant changes in the parameters following abatacept therapy. As this was a pilot study comprising relatively small numbers, Bonferroni correction was not applied. Any significant changes observed posttreatment would represent trends for potential further evaluation.

\section{Gene expression data}

Summary statistics and their mean changes and mean percentage changes from baseline were provided for mRNA levels of pro-inflammatory markers for responders, non-responders and the overall patient population. Mean and mean 
Figure 1 (A) Median change in synovial expression of cellular infiltrate after 4 months of treatment with abatacept. Multiple synovial biopsies were obtained from representative inflamed sites and stained with antibodies to a range of synovial markers. Synovial lining layer (LL) and sub-lining layer (SL) expression of each marker was scored semiquantitatively on a five-point scale $(0$, minimal infiltration; 4, maximal infilatration) and a median percentage change from baseline calculated.

${ }^{*} p<0.05$. Error bars represent 25th and 75th percentiles; the number of patients analysed was 11 in all cases. (B) Example of CD68 expression in paired synovial tissue samples from a patient with rheumatoid arthritis treated with abatacept. Panels I and II are the negative controls for the patient at baseline and post-abatacept, respectively. Panels III and IV demonstrate macrophage (CD68) staining at baseline and post-abatacept, respectively. Considerable LL and SL CD68 expression is observed in the baseline biopsy; expression continues to be marked post-abatacept. ICAM-1, intercellular adhesion molecule type 1.

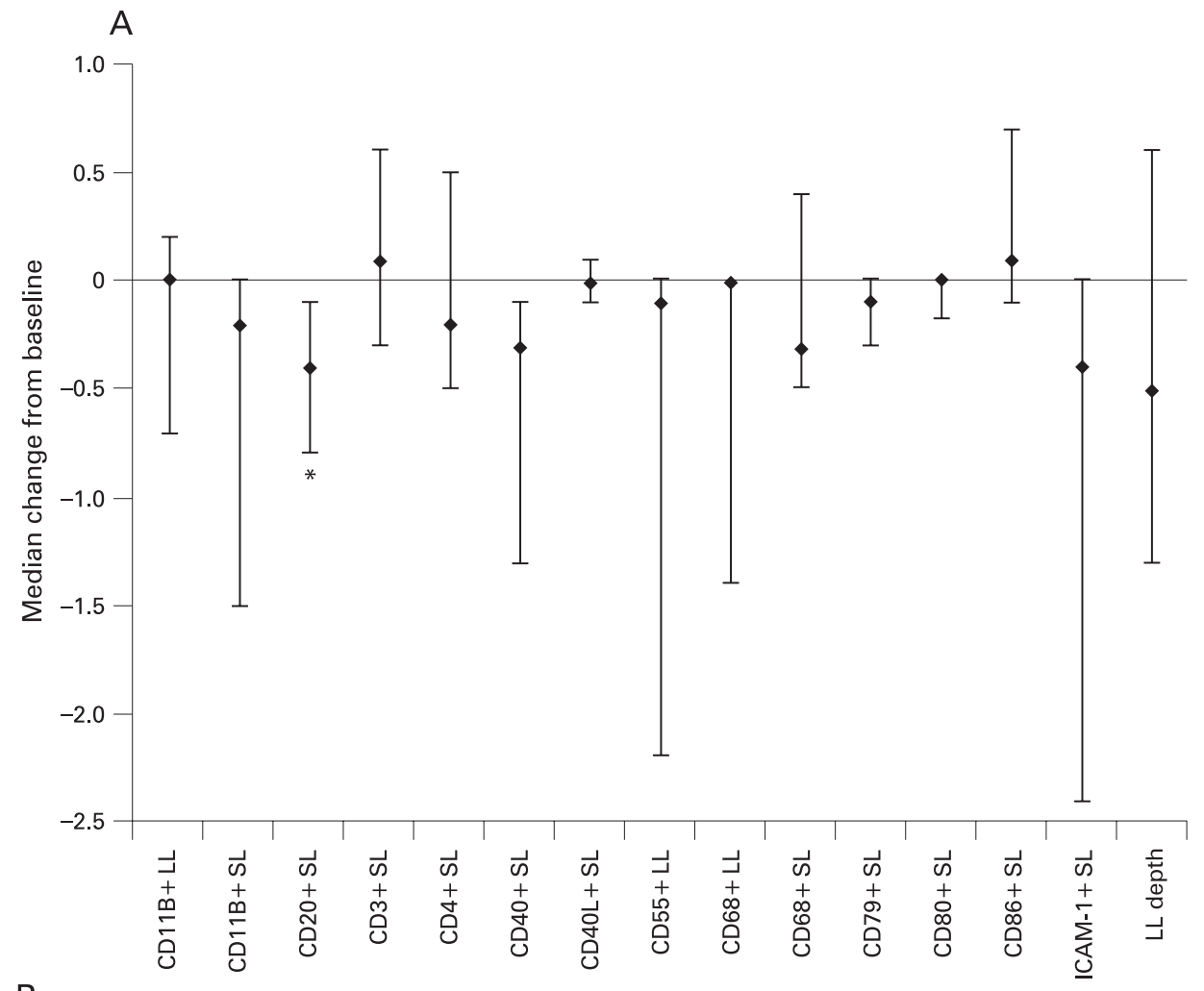

B

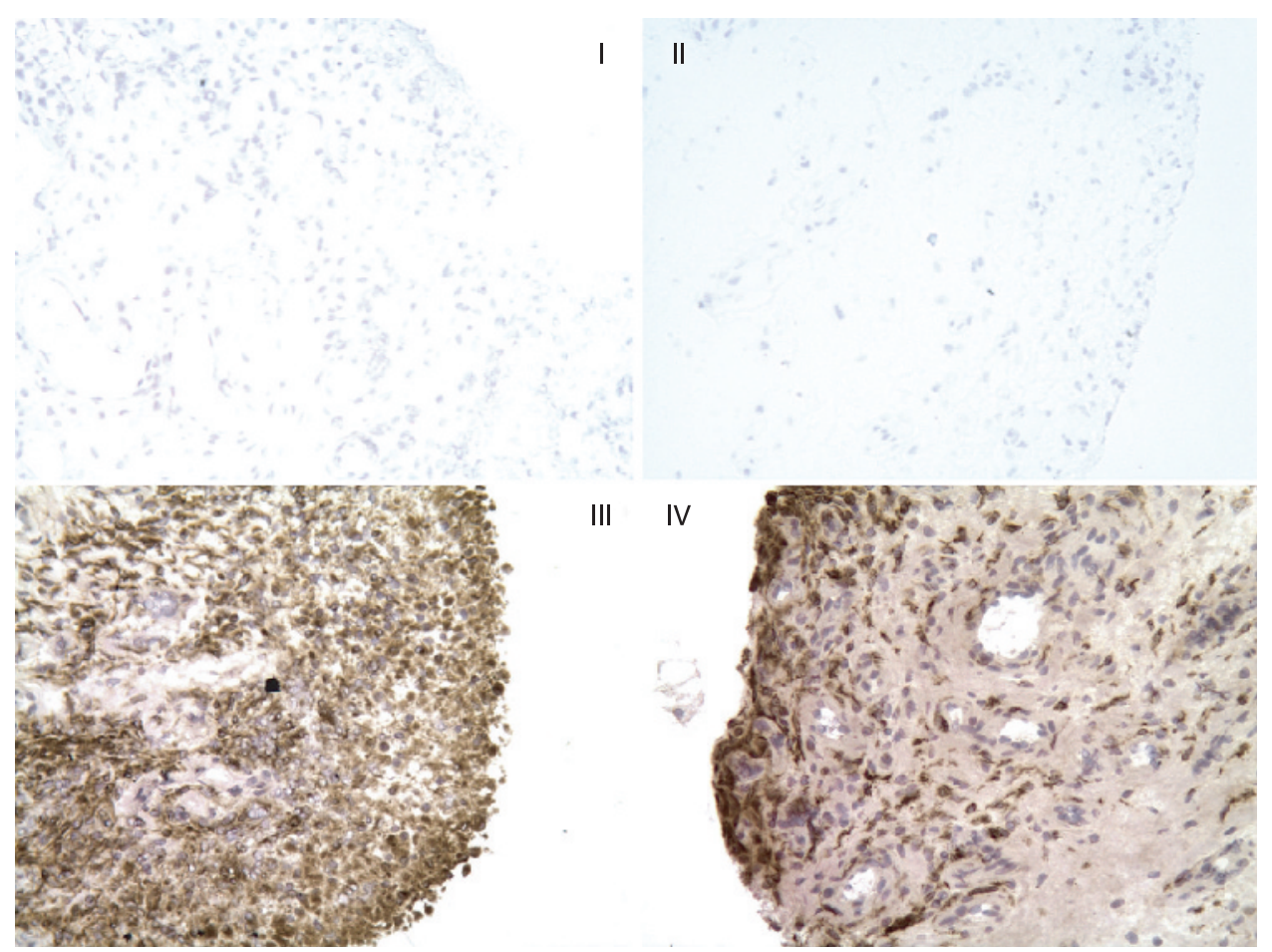


Figure 2 Geometric mean percentage change in synovial gene expression in patients after 4 months of treatment with abatacept in (A) all patients combined $\left(\mathrm{n}=14^{\dagger}\right),(\mathrm{B})$ disease activity score 28 (DAS28) responders $\left(n=8^{\dagger}\right)$ versus DAS28 non-responders $\left(n=6^{\dagger}\right)$. RNA was isolated from the synovium using chloroform extraction and reverse transcribed to cDNA. mRNA levels of tumour necrosis factor alpha (TNF $\alpha$ ), IL$1 \beta$, IL-6, matrix metalloprotease (MMP) 1, MMP-3, IFN $\gamma$, receptor activator of nuclear factor kappa B (RANK), RANK ligand (RANKL) and osteoprotegerin (OPG) were quantified using TaqMan quantitative PCR analysis. Data are expressed as the geometric mean percentage change in gene expression relative to baseline. Error bars represent $95 \% \mathrm{Cl} .{ }^{*} 95 \% \mathrm{Cl}$ do not include zero. Two patients (one responder and one non-responder) had IFN $\gamma$ levels below the detectable limit at baseline and one patient (non-responder) had IL-6 levels below the detectable limit at baseline; these patients were excluded from analysis for these cytokines. Wald statistics indicate a significant treatment effect of abatacept on IFN $\gamma$, IL-1 $\beta$, IL-6, MMP-1 and MMP-3 simultaneously $(\mathrm{p}<0.01)$.

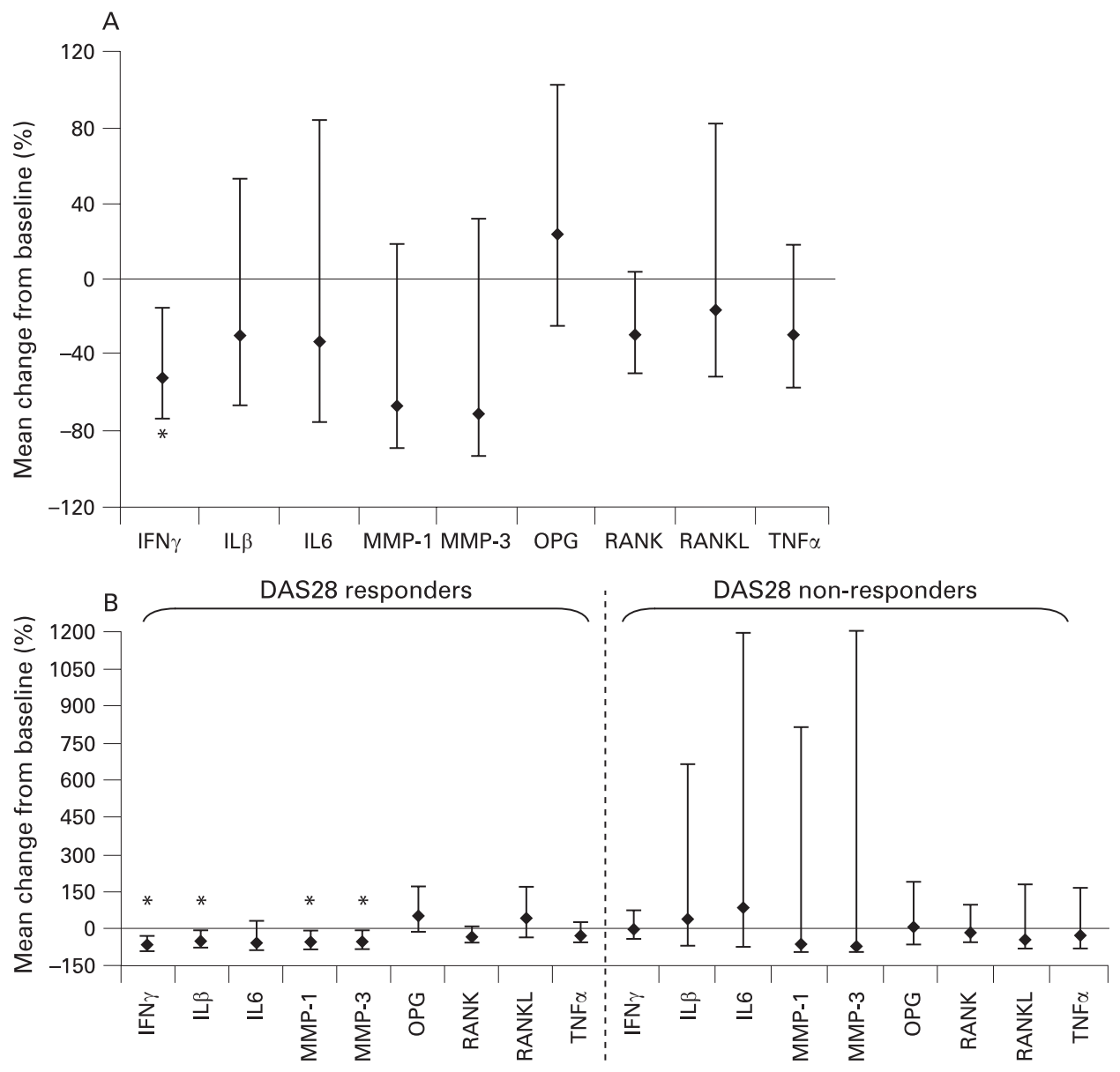

percentage changes of log-transformed PCR data were expressed as geometric mean and the geometric mean percentage changes, respectively. Point estimates and the two-sided $95 \% \mathrm{CI}$ on the log scale were exponentiated to obtain estimates on the original scale.

The treatment effect on all pro-inflammatory gene expression was tested simultaneously using mean treatment effects and their covariance matrix in post-hoc analyses based on Wald statistics; a $p$ value of less than 0.01 indicates a significant treatment effect on the parameters simultaneously.

\section{Magnetic resonance imaging}

Median values of ME and IRE were calculated by dividing the sum IRE or ME results for each ROI by the number of pixels enhancing within the ROI. Median values of percentage change from baseline for ME and IRE were calculated. The post-hoc Pearson correlation test evaluated for a relationship between the gene expression data and MRI outcomes.

\section{RESULTS}

\section{Baseline patient demographics and disease characteristics}

Sixteen patients were recruited (13 female; mean age 53.8 years); 15 completed the study (one patient dropped out due to elective toe surgery) (table 1). Twelve of the 15 patients had received more than one TNF-blocking agent, 12 were on concomitant methotrexate, $75 \%$ of patients were rheumatoid factor positive. Mean baseline DAS28 was 7.1 (SEM 0.22), with mean swollen and tender joint counts of 14.0 (SD 6.0) and 19.2 (SD 7.2), respectively. High baseline inflammatory markers were noted with a mean C-reactive protein (CRP) level of $5.8 \mathrm{mg} / \mathrm{dl}$ (SD 5.6) and ESR of $58.9 \mathrm{~mm} / \mathrm{h}$ (SD 27.0).

\section{Clinical response}

A gradual (significant) decline in overall DAS28 was recorded, with mean DAS28 at baseline, day 57 and day 120 of 7.1 (SEM $0.22 ; \mathrm{n}=16$ ), 6.13 (SEM 0.34; $\mathrm{n}=14$ ) and 5.77 (SEM 0.37; $\mathrm{n}=15)$, respectively $(\mathrm{p}<0.01)$. Nine of the 15 patients $(60 \%)$ completing the study demonstrated a clinical response to abatacept treatment (reduction in DAS28 of $\geqslant 1.2$ ). Ten of the 15 patients demonstrated a "moderate" EULAR response; one patient had a "good" EULAR response. A median (25th, 75th percentile) percentage reduction in CRP of $66.7 \%(90.0 \%$, $44.4 \%$ ) was noted from baseline. No significant differences in the baseline clinical features were observed between the clinical response and non-response groups (data not shown).

\section{Immunohistochemistry}

Small reductions in some of the synovial markers analysed were observed following abatacept treatment (fig 1A). A modest but significant $(p<0.05)$ reduction in SL CD20 was noted from baseline (0.83) to day $120(0.42)$, with a median change (25th, 75 th percentile) of $-0.4(-0.8,-0.1)$. A trend for reduction in the SL baseline and posttreatment values was observed for CD11b (2.35 and 1.93), CD68 (2.52 and 2.33), CD40 (1.04 and $0.48)$, CD79 (0.21 and 0.08) and intercellular adhesion molecule type 1 (3.16 and 2.18). Trends in LL reductions from baseline to posttreatment, respectively, were also seen for CD68 (3.58 and 3.0) and CD55 (2.93 and 2.28) with a small reduction in LL 


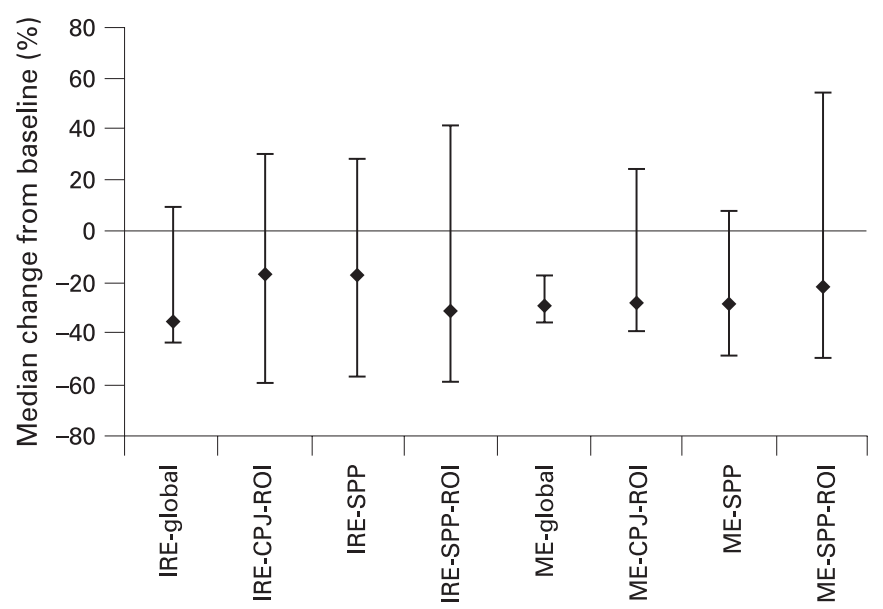

Figure 3 Median percentage change in key magnetic resonance imaging (MRI) measures. MRI of the knee was performed, and measures of the initial rate of enhancement (IRE) and maximal enhancement (ME) made in the global region as well as in regions of interest (ROI) at the cartilage-pannus junction (CPJ) and the suprapatellar pouch (SSP).

Values for the ME and IRE are calculated from the sum of the enhancing pixels in each region of interest, expressed as arbitrary units. Error bars represent 25 th and 75 th percentiles.

depth from 1.45 to 0.96 (fig 1A), although these changes were highly variable. Figure 1B shows CD68 expression in representative paired synovial tissue samples, in which the degree of expression is largely unchanged following abatacept treatment.

\section{Gene expression analysis}

In the total population, a significant $(p<0.05)$ geometric mean percentage change in IFN $\gamma$ gene expression of $-52 \%(95 \% \mathrm{CI}$ -73 to -15 ) was observed (fig $2 \mathrm{~A}$ ). In addition, reductions (non-significant) in IL-1 $\beta$, IL-6, MMP-1, MMP-3 and TNF $\alpha$ gene expression were noted. Interestingly, a decreasing trend in receptor activator of nuclear factor kappa B (RANK) and RANK ligand (RANKL) gene expression was seen in association with an increase in osteoprotegerin gene expression (fig 2A).

The mean treatment effects of IFN $\gamma$, IL-1 $\beta$, IL- 6, MMP-1 and MMP-3 (-0.32, $-0.27,-0.23,-0.62$ and -0.67 , respectively) and their covariance matrix were estimated. Using Wald statistics, a value of $p<0.01$ was noted, indicating a significant treatment effect of abatacept on these parameters simultaneously.

Analysis of the responder (reduction in DAS28 score of $\geqslant 1.2$; $\mathrm{n}=7$ ) and non-responder groups demonstrated significant reductions $(p<0.05)$ in IFN $\gamma$ gene expression in the responder group only, with a mean percentage change of $-69 \%(95 \% \mathrm{CI}$ -87 to -27 ) (fig $2 B$ ). Significant reductions $(p<0.05)$ in additional parameters were also observed, namely mean percentage change in gene expression of IL-1 $\beta(-53 \%$; $95 \% \mathrm{CI}$ -77 to -6$)$, MMP-1 (-61\%; $95 \%$ CI -83 to -11$)$ and MMP-3 $(-59 \%$; $95 \%$ CI -82 to -5$)$ (fig $2 \mathrm{~B})$. In addition, osteoprotegerin expression increased posttreatment (geometric percentage mean change of $53 \%$ in responders).

Immunohistochemistry demonstration of reduced synovial Bcell expression was confirmed by a reduction in CD19 transcript levels (data not shown) although IgM transcript levels were unchanged.

\section{Magnetic resonance imaging}

For the total population, a significant median percentage reduction from baseline in ME-global of $-28.5 \% \quad(p=0.001)$
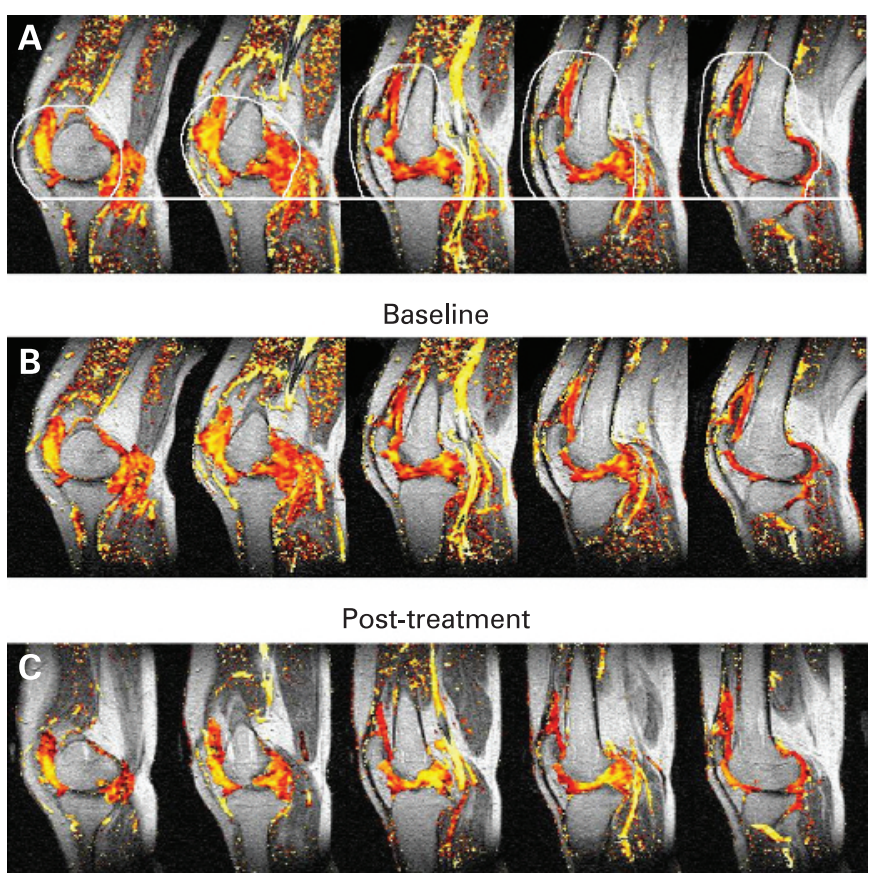

Figure 4 Five characteristic dynamic gadolinium-enhanced magnetic resonance imaging sagittal scans acquired from the knee with superimposed colour data showing values of initial rate of enhancement (IRE) across synovial space following gadolinium enhancement-pixels shown in yellow represent high IRE values whereas red show relatively lower values. Image (A) shows global region of interest outlined in white, which defines the extent of the synovitis at a level of 10 pixels below the tibial plateau to the top of the suprapatellar pouch, avoiding enhancement from muscle and arteries in each of the five sagittal images. Images (B) and (C) are an example of pre and posttreatment, respectively.

was observed with a reduction also in the IRE-global of $-34.9 \%$. Eleven of 15 patients $(73.3 \%)$ showed a reduction in IRE-global and 14 of 15 patients (93.3\%) in ME-global pre to posttreatment, indicating a reduction in synovitis. There was a greater reduction in IRE-global in clinical responders compared with non-responders (median percentage change $-42 \%$ and $-10 \%$, respectively); however, there was no significant difference in changes in ME-global between clinical responders and nonresponders. The data for the smaller ROI were more variable and no consistent changes were observed across the whole study population. Figure 3 presents the median percentage change from baseline in key MRI measures for the total population. Results include DCE-MRI parameters within the global region as well as ROI at the CPJ and the SPP. Figure 4 shows representative example of a DCE-MRI image with the area used to compute global IRE and $\mathrm{ME}$ and images showing changes in DCE-MRI pre and post-abatacept treatment. Pearson correlation analyses were undertaken to evaluate for a relationship between the gene expression data and MRI outcomes. A good correlation between IFN $\gamma$ and IRE-global, as well as ME-global, was observed (fig 5; $\mathrm{r}=0.628$ and $0.7863)$.

\section{DISCUSSION}

Abatacept, a modulator of T-cell co-stimulation, has demonstrated efficacy and an acceptable safety profile in patients with RA and an inadequate response to methotrexate ${ }^{7}$ and in the challenging group of patients resistant to TNF blockade. ${ }^{8}$ Little 

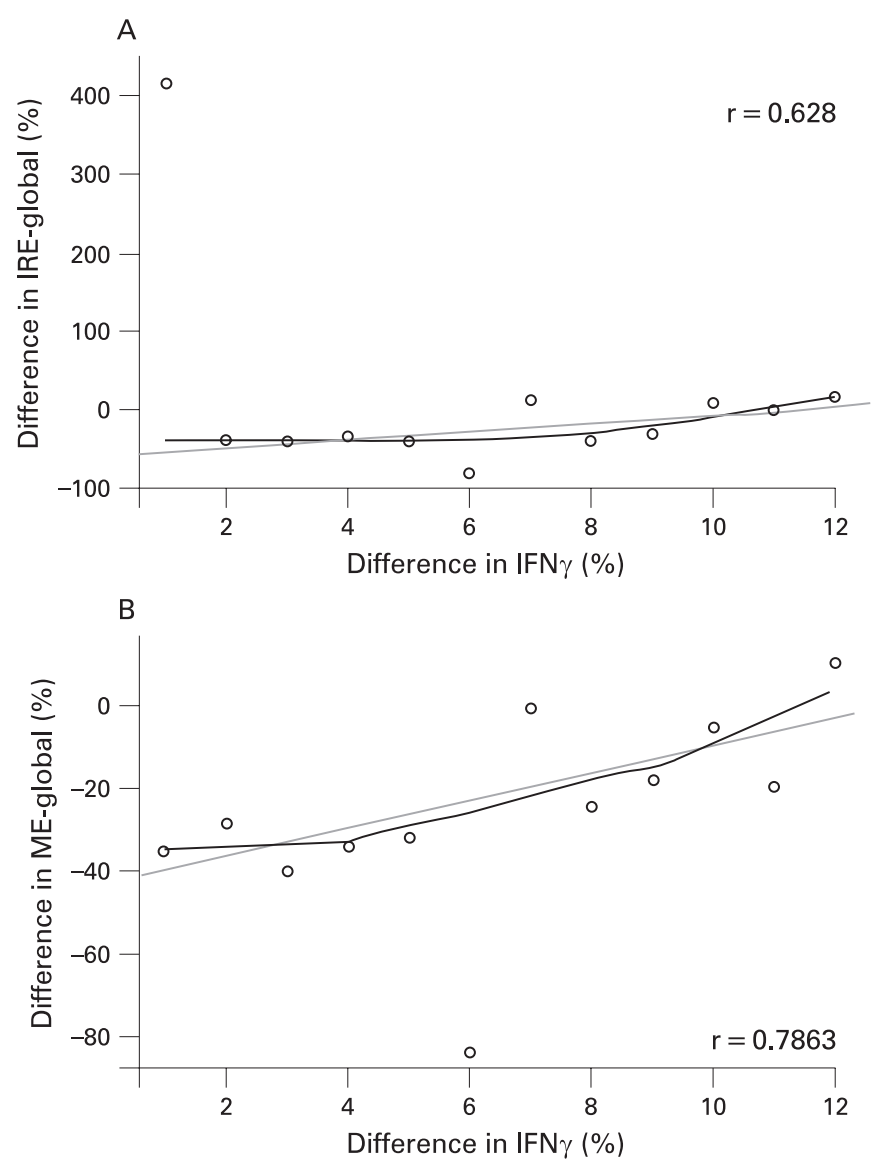

Figure 5 The relationship between the IFN $\gamma$ gene expression and magnetic resonance imaging (MRI) outcomes. Pearson correlation analyses were carried out to evaluate the relationship between gene expression data and MRI outcomes. A good correlation between IFN $\gamma$ and the initial rate of enhancement (IRE)-global, as well as maximal enhancement (ME)-global was observed.

information is available on the changes that occur with abatacept on the synovium, the primary site of disease. This study is the first to evaluate the mechanistic effects of abatacept, with particular focus on TNF blockade failures. The findings demonstrate contrasting synovial changes: a clear generalised reduction in synovial pro-inflammatory gene expression (particularly IFN $\gamma$ ), but with little change in the composition of the synovial infiltrate. In particular, the reduction in synovial IFN $\gamma$ is consistent with a T-cell-dependent mechanism of action. The improvement observed in imaging outcomes with reduced tissue perfusion and vascular permeability (indicative of inflammation and correlated with synovial volume $)^{15}$ complements these findings further.

Improved understanding of T-cell biology, with recognition of antigen-independent $\mathrm{T}$-cell influences strongly supports the involvement of $\mathrm{T}$ cells in RA pathogenesis. ${ }^{16}{ }^{17}$ The relative inefficacy of $\mathrm{T}$-cell depletion strategies led to the concept of modulating as opposed to depleting T-cell function, with the targeting of one of the more prominent $\mathrm{T}$-cell co-stimulatory signals, the CD28:CD80/CD86, by interaction with abatacept.

This hypothesis-generating study specifically concentrated on patients failing one or more TNF antagonists. Several studies to date have utilised synovial immunohistochemistry to evaluate the effects of therapeutic intervention. ${ }^{11}{ }^{18-20}$ In this collaborative study, we chose to complement this technique with a validated method of real-time quantitative PCR utilising pooled biopsy fragments for gene expression analysis. DCE-MRI was included to correlate the clinical and synovial data with refined synovial imaging.

Sixty per cent of patients treated with abatacept demonstrated a significant improvement in disease activity (DAS28 reduction of $\geqslant 1.2$ ). Although the DAS28 remained high, suggesting only a modest clinical improvement, these data are consistent with a resistant cohort and mimic the published trial data that formed the basis for the approval of abatacept and rituximab in TNF blockade failures. ${ }^{821}$

Several key points can be learned from this study. Only a modest reduction in cellular infiltrate composition was observed with abatacept, and surprisingly this was found mainly in the B-cell population; this is in marked contrast to similar studies conducted to assess the effect of TNF blockade, which revealed significant reductions in cellularity (including macrophage populations). ${ }^{11}{ }^{18-20}$ The modest clinical improvement could account for these findings; however, this difference is not necessarily a surprise when one considers the nature of the targets. TNF $\alpha$ is a pleiotropic cytokine, the effects of which include promoting the recruitment of inflammatory infiltrate and the induction of adhesion molecules. Conversely, abatacept does not directly target the $\mathrm{T}$ cell; by targeting the more classic co-stimulatory signal, selective modulation of T-cell activation occurs. Notably, there was no significant decrease in the number of SL macrophages even though others have proposed CD68+ cell depletion as a primary biomarker predictive of clinical response. ${ }^{22}$ We would suggest the importance of considering novel mechanisms of action despite the findings contrasting with previously held assumptions. Semiquantitative as opposed to quantitative analysis could be argued also to account for the relative negative findings, although previous studies have demonstrated the ability of this method to demonstrate significant changes after effective treatment. ${ }^{11}{ }^{23-26}$ In addition, the significant reduction in CD20 in the responder group suggests the sensitivity of the method.

This observed reduction in CD20+ cells also suggests more of a modulating as opposed to cellular-depleting effect of abatacept; In fact, human cytotoxic T-lymphocyte antigen type 4 immunoglobulin binds CD80/CD86 on B cells, ${ }^{27}$ as well as $T$ cells. Further detailed studies are required to explore this observation, including an evaluation of synovial germinal centre formation and other markers of B-cell biology.

In contrast to the histology, the gene expression study demonstrated diminution in pro-inflammatory gene expression, with significant reductions in MMP-1 and MMP-3, and smaller reductions in TNF $\alpha$, IL- $1 \beta$ and IL-6. This is consistent with a previous study that also illustrated a reduction in MMP gene expression following effective treatment. ${ }^{28} \mathrm{MMP}$ expression, being an "integration" of all of the pro-inflammatory signals, would explain the more pronounced reduction in MMP gene expression compared with the individual cytokines. These findings are emphasised with a demonstration of treatment effect on pro-inflammatory gene expression simultaneously (Wald statistic). The significant reduction in IFN $\gamma$ gene expression, however, certainly suggests an effective functional effect of T-cell modulation on the synovium. Although comprising small numbers, comparison of the abatacept response and non-response groups further verifies this observation, with significant reductions in MMP-1, MMP-3 and IL-1 $\beta$ gene expression, in addition to IFN $\gamma$ gene expression noted in the response group. A reduction in CD19 transcript levels was consistent with the immunohistochemistry findings; interestingly, IgM transcripts did not change, suggesting the B-cell 
effect is different to that noted with anti-CD20 both in magnitude and character. ${ }^{29}$

Another interesting finding from this study was the divergent (and advantageous) trend observed between RANK/RANKL and osteoprotegerin gene expression. Osteoprotegerin inhibits the effects of the RANK/RANKL interaction by competing with RANK, thereby functioning as a soluble decoy receptor for RANKL. The reduction in RANK/RANKL expression with concomitant osteoprotegerin upregulation is consistent with a more regulatory influence on osteoclast cell differentiation and bone resorption. Whereas the exact mechanism underlying this observation is unclear, it correlates well with the radiological improvement that has been reported with abatacept therapy. ${ }^{\text {? }}$

DCE-MRI was undertaken pre and post-abatacept therapy, with measurement of rates of contrast enhancement (IRE and ME, shown to correlate with inflammatory activity and blood vessel density) ${ }^{15}$ confirming a general reduction in the IRE and $M E$ values of all regions evaluated, with a significant reduction in ME-global. The inability to detect a significant reduction in the global IRE and lack of consistent change in the small ROI is likely to reflect the relatively small sample size, response heterogeneity and/or reproducibility of DCE-MRI measurements. In addition, the differences between responders and nonresponders make it harder to detect a reduction in the group as a whole. Nevertheless, the correlation between the MRI parameters and IFN $\gamma$ gene expression further suggests the synovium as a site of action for abatacept.

Several limitations must also be considered in the interpretation of these data. First, as a result of ethical considerations we did not include a placebo arm. Second, the study population was small and comprised patients with severe disease who were refractive to previous treatment; other similar studies in this population have shown limited changes and a large variation in responses. ${ }^{29}{ }^{30}$ Finally, it is possible that the primary impact of abatacept may be at another site, such as secondary lymphoid organs.

In summary, we report the first mechanistic study incorporating DCE-MRI and tissue for immunohistochemistry and quantitative real-time PCR analyses before and after abatacept therapy. These results demonstrate a treatment effect on inflammatory mediators simultaneously, with convincing effect on IFN $\gamma$, confirming a functional $\mathrm{T}$-cell effect. This contrasts with a modest histological change, suggesting deactivation rather than depopulation of the synovium, although a reduction in synovial "quantity" is observed as evidenced by the MRI. Finally, this reduction in inflammation correlates well with the effect on IFN $\gamma$. Overall, the study findings are in keeping with the immunomodulatory nature of selective co-stimulation. The changes in bone biology and B cells add an interesting dimension to the potential effect and mechanism of action of co-stimulation modulation. Further lines of investigation in a larger patient population should further elucidate the synovial effects of co-stimulation modulation with abatacept.

Acknowledgements: The author/s would like to thank Karen Henshaw and Diane

Funding: This study was funded and sponsored by Bristol-Myers Squibb, Princeton, New Jersey, USA.

Competing interests: PE has provided expert advice and undertaken clinical trials for Bristol-Myers Squibb.

Ethics approval: Leeds research ethics committee approval was obtained before study initiation. The study was conducted in accordance with the ethical principles of the Declaration of Helsinki.

Patient consent: Obtained.

\section{REFERENCES}

1. Weinblatt ME, Kremer JM, Bankhurst AD, Bulpitt KJ, Fleischmann RM, Fox RI, et al. A trial of etanercept, a recombinant tumor necrosis factor receptor:Fc fusion protein, in patients with rheumatoid arthritis receiving methotrexate. $N$ Engl J Med 1999;340:253-9.

2. Lipsky PE, van der Heijde DM, St Clair EW, Furst DE, Breedveld FC, Kalden JR, et al. Infliximab and methotrexate in the treatment of rheumatoid arthritis. Anti-Tumor Necrosis Factor Trial in Rheumatoid Arthritis with Concomitant Therapy Study Group. N Engl J Med 2000;343:1594-602.

3. Criscione LG, St Clair EW. Tumor necrosis factor-alpha antagonists for the treatment of rheumatic diseases. Curr Opin Rheumatol 2002;14:204-11.

4. Weinblatt ME, Keystone EC, Furst DE, Moreland LW, Weisman MH, Birbara CA, et al. Adalimumab, a fully human anti-tumor necrosis factor alpha monoclonal antibody, for the treatment of rheumatoid arthritis in patients taking concomitant methotrexate: the ARMADA trial. Arthritis Rheum 2003;48:35-45.

5. Linsley PS, Brady W, Urnes M, Grosmaire LS, Damle NK, Ledbetter JA. CTLA-4 is a second receptor for the B cell activation antigen B7. J Exp Med 1991;174:561-9.

6. Mackie SL, Vital EM, Ponchel F, Emery P. Co-stimulatory blockade as therapy for rheumatoid arthritis. Curr Rheumatol Rep 2005;7:400-6.

7. Kremer JM, Genant HK, Moreland LW, Russell AS, Emery P, Abud-Mendoza C, et al. Effects of abatacept in patients with methotrexate-resistant active rheumatoid arthritis: a randomized trial. Ann Intern Med 2006;144:865-76

8. Genovese MC, Becker JC, Schiff M, Luggen M, Sherrer Y, Kremer J, et al. Abatacept for rheumatoid arthritis refractory to tumor necrosis factor alpha inhibition. N Engl J Med 2005;353:1114-23.

9. Arnett FC, Edworthy SM, Bloch DA, McShane DJ, Fries JF, Cooper NS, et al. The American Rheumatism Association 1987 revised criteria for the classification of rheumatoid arthritis. Arthritis Rheum 1988;31:315-24.

10. Ledingham J, Deighton C. Update on the British Society for Rheumatology guidelines for prescribing TNFalpha blockers in adults with rheumatoid arthritis (update of previous guidelines of April 2001). Rheumatology (Oxford) 2005;44:157-63.

11. Tak PP, Taylor PC, Breedveld FC, Smeets TJ, Daha MR, Kluin PM, et al. Decrease in cellularity and expression of adhesion molecules by anti-tumor necrosis factor alpha monoclonal antibody treatment in patients with rheumatoid arthritis. Arthritis Rheum 1996;39:1077-81.

12. Boyle DL, Rosengren S, Bugbee W, Kavanaugh A, Firestein GS. Quantitative biomarker analysis of synovial gene expression by real-time PCR. Arthritis Res Ther 2003;5:R352-60.

13. Reece RJ, Kraan MC, Radjenovic A, Veale DJ, O'Connor PJ, Ridgway JP, et al. Comparative assessment of leflunomide and methotrexate for the treatment of rheumatoid arthritis, by dynamic enhanced magnetic resonance imaging. Arthritis Rheum 2002; 46:366-72.

14. Rhodes LA, Tan AL, Tanner SF, Radjenovic A, Hensor EM, Reece R, et al. Regional variation and differential response to therapy for knee synovitis adjacent to the cartilage-pannus junction and suprapatellar pouch in inflammatory arthritis: implications for pathogenesis and treatment. Arthritis Rheum 2004;50:2428-32.

15. Tofts PS. Modeling tracer kinetics in dynamic Gd-DTPA MR imaging. J Magn Reson Imaging 1997; 7:91-101.

16. Firestein GS. Evolving concepts of rheumatoid arthritis. Nature 2003;423:356-61.

17. Choy EH, Panayi GS. Cytokine pathways and joint inflammation in rheumatoid arthritis. N Engl J Med 2001;344:907-16.

18. Taylor PC, Peters AM, Paleolog E, Chapman PT, Elliott MJ, McCloskey R, et al. Reduction of chemokine levels and leukocyte traffic to joints by tumor necrosis factor alpha blockade in patients with rheumatoid arthritis. Arthritis Rheum 2000;43:38-47.

19. Smeets TJ, Kraan MC, van Loon ME, Tak PP. Tumor necrosis factor alpha blockade reduces the synovial cell infiltrate early after initiation of treatment, but apparently not by induction of apoptosis in synovial tissue. Arthritis Rheum 2003;48:2155-62.

20. Catrina Al, Trollmo C, af Klint E, Engstrom M, Lampa J, Hermansson Y, et al. Evidence that anti-tumor necrosis factor therapy with both etanercept and infliximab induces apoptosis in macrophages, but not lymphocytes, in rheumatoid arthritis joints: extended report. Arthritis Rheum 2005;52:61-72.

21. Cohen SB, Emery P, Greenwald MW, Dougados M, Furie RA, Genovese MC, et al Rituximab for rheumatoid arthritis refractory to anti-tumor necrosis factor therapy: results of a multicenter, randomized, double-blind, placebo-controlled, phase III trial evaluating primary efficacy and safety at twenty-four weeks. Arthritis Rheum 2006;54:2793-806

22. Bresnihan B, Gerlag DM, Rooney T, Smeets TJ, Wijbrandts CA, Boyle D, et al. Synovial macrophages as a biomarker of response to therapeutic intervention in rheumatoid arthritis: standardization and consistency across centers. J Rheumatol 2007;34:620-2

23. Koch AE, Robinson PG, Radosevich JA, Pope RM. Distribution of CD45RA and CD45R0 T-lymphocyte subsets in rheumatoid arthritis synovial tissue. J Clin Immunol 1990;10:192-9

24. Tak PP, van der Lubbe PA, Cauli A, Daha MR, Smeets TJ, Kluin PM, et al. Reduction of synovial inflammation after anti-CD4 monoclonal antibody treatment in early rheumatoid arthritis. Arthritis Rheum 1995;38:1457-65.

25. Veale DJ, Reece RJ, Parsons W, Radjenovic A, O'Connor PJ, Orgles CS, et al. Intraarticular primatised anti-CD4: efficacy in resistant rheumatoid knees. A study of combined arthroscopy, magnetic resonance imaging, and histology. Ann Rheum Dis 1999;58:342-9.

26. Yanni G, Whelan A, Feighery C, Bresnihan B. Synovial tissue macrophages and joint erosion in rheumatoid arthritis. Ann Rheum Dis 1994;53:39-44. 
27. Hathcock KS, Laszlo G, Pucillo C, Linsley P, Hodes RJ. Comparative analysis of B7-1 and B7-2 costimulatory ligands: expression and function. J Exp Med 1994;180:631-40.

28. Gerlag DM, Haringman JJ, Smeets TJ, Zwinderman AH, Kraan MC, Laud PJ, et al. Effects of oral prednisolone on biomarkers in synovial tissue and clinical improvement in rheumatoid arthritis. Arthritis Rheum 2004;50:3783-91.
29. Kavanaugh A, Rosengren S, Lee SJ, Hammaker D, Firestein GS, Kalunian K, et al. Assessment of rituximab's immunomodulatory synovial effects (the ARISE trial). I: clinical and synovial biomarker results. Ann Rheum Dis 2007:67:402-8.

30. Vos K, Thurlings RM, Wijbrandts CA, van Schaardenburg D, Gerlag DM, Tak PP. Early effects of rituximab on the synovial cell infiltrate in patients with rheumatoid arthritis. Arthritis Rheum 2007:56:772-8. 


\section{Corrections}

The department of one of the authors who co-authored all of the below papers has found that the affiliations were not correct. The correct affiliations for Professor P Emery, for all of the below articles, are: ${ }^{1}$ Section of Musculoskeletal Disease, Leeds Institute of Molecular Medicine, University of Leeds; ${ }^{2}$ NIHR Leeds Musculoskeletal Biomedical Research Unit, Leeds Teaching Hospitals Trust, Leeds, UK.

1. Keystone E, Emery P, Peterfy CG, et al. Rituximab inhibits structural joint damage in patients with rheumatoid arthritis with an inadequate response to tumour necrosis factor inhibitor therapies. Ann Rheum Dis 2009;68:216-21.

2. Doward LC, McKenna SP, Whalley D, et al. The development of the L-OoL: a quality-of-life instrument specific to systemic lupus erythematosus. Ann Rheum Dis 2009;68:196-200.

3. Potter C, Hyrich KL, Tracey A, et al. Association of rheumatoid factor and anticyclic citrullinated peptide positivity, but not carriage of shared epitope or PTPN22 susceptibility variants, with anti-TNF response in RA. Ann Rheum Dis 2009;68:69-74.

4. Smolen JS, Han C, van der Heijde DM, et al.; Active-Controlled Study of Patients Receiving Infliximab for the Treatment of Rheumatoid Arthritis of Early Onset (ASPIRE) Study Group. Radiographic changes in rheumatoid arthritis patients attaining different disease activity states with methotrexate monotherapy and infliximab plus methotrexate: the impacts of remission and tumour necrosis factor blockade. Ann Rheum Dis 2009;68:823-7.

5. Buch MH, Boyle DL, Rosengren S, et al. Mode of action of abatacept in rheumatoid arthritis patients having failed tumour necrosis factor blockade: a histological, gene expression and dynamic magnetic resonance imaging pilot study. Ann Rheum Dis 2009;68:1220-7.

6. Emery P, Van Vollenhoven R, Ostergaard M, et al. Guidelines for initiation of antitumour necrosis factor therapy in rheumatoid arthritis: similarities and differences across Europe. Ann Rheum Dis 2009;68:456-9.

7. Bejarano V, Conaghan PG, Proudman SM, et al. Long-term efficacy and toxicity of ciclosporin A in combination with methotrexate in poor prognosis rheumatoid arthritis Ann Rheum Dis 2009;68:761-3.

8. Rudwaleit M, Landewé R, van der Heijde D, et al. The development of Assessment of SpondyloArthritis international Society classification criteria for axial spondyloarthritis (part I): classification of paper patients by expert opinion including uncertainty appraisal. Ann Rheum Dis 2009;68:770-6.

9. Bennett AN, Marzo-Ortega H, Emery P, et al.; Leeds Spondyloarthropathy Group. Diagnosing axial spondyloarthropathy. The new Assessment in SpondyloArthritis international Society criteria: MRI entering centre stage. Ann Rheum Dis 2009;68:765-7.

10. Marzo-Ortega H, McGonagle D, O'Connor P, et al. Baseline and 1-year magnetic resonance imaging of the sacroiliac joint and lumbar spine in very early inflammatory back pain. Relationship between symptoms, HLA-B27 and disease extent and persistence. Ann Rheum Dis 2009;68:1721-7.

11. Gilworth G, Emery P, Gossec L, et al. Adaptation and cross-cultural validation of the rheumatoid arthritis work instability scale (RA-WIS). Ann Rheum Dis 2009;68:1686-90.

12. Gilworth G, Emery P, Gossec L, et al. Adaptation and cross-cultural validation of the RA-WIS (Work Instability Scale). Ann Rheum Dis 2009;68:1686-90.

13. Jarrett SJ, Sivera F, Cawkwell LS, et al. MRI and clinical findings in patients with ankylosing spondylitis eligible for anti-tumour necrosis factor therapy after a short course of etoricoxib. Ann Rheum Dis 2009;68:1466-9.

14. Haugeberg G, Conaghan PG, Quinn $\mathrm{M}$, et al. Bone loss in patients with active early rheumatoid arthritis: infliximab and methotrexate compared with methotrexate treatment alone. Explorative analysis from a 12-month randomised, double-blind, placebo-controlled study. Ann Rheum Dis 2009;68:1898-901.

15. Genovese MC, Breedveld FC, Emery P, et al. Safety of biological therapies following rituximab treatment in rheumatoid arthritis patients. Ann Rheum Dis 2009;68:1894-7

16. Kekow J, Moots RJ, Emery P, et al. Patient-reported outcomes improve with etanercept plus methotrexate in active early rheumatoid arthritis and the improvement is strongly associated with remission: the COMET trial. Ann Rheum Dis 2010;69:222-5

17. Furst DE, Keystone EC, Fleischmann R, et al. Updated consensus statement on biological agents for the treatment of rheumatic diseases, 2009. Ann Rheum Dis 2010;69(Suppl 1):i2-29.

18. Freeston JE, Wakefield RJ, Conaghan PG, et al. A diagnostic algorithm for persistence of very early inflammatory arthritis: the utility of power Doppler ultrasound when added to conventional assessment tools. Ann Rheum Dis 2010;69:417-9.

19. Jones $\mathbf{E}$, Churchman SM, English A, et al. Mesenchymal stem cells in rheumatoid synovium: enumeration and functional assessment in relation to synovial inflammation level. Ann Rheum Dis 2010;69:450-7.

20. Alten RE, Zerbini C, Jeka S, et al. Efficacy and safety of pamapimod in patients with active rheumatoid arthritis receiving stable methotrexate therapy. Ann Rheum Dis 2010;69:364-7.
21. Machold KP, Landewé R, Smolen JS, et al. The Stop Arthritis Very Early (SAVE) trial, an international multicentre, randomised, double-blind, placebo-controlled trial on glucocorticoids in very early arthritis. Ann Rheum Dis 2010;69:495-502.

22. Schoels M, Knevel R, Aletaha D, et al. Evidence for treating rheumatoid arthritis to target: results of a systematic literature search. Ann Rheum Dis 2010;69:638-43.

23. Smolen JS, Aletaha D, Bijlsma JW, et al.; T2T Expert Committee. Treating rheumatoid arthritis to target: recommendations of an international task force. Ann Rheum Dis 2010;69:631-7.

24. Burr ML, Naseem H, Hinks A, et al.; BIRAC Consortium; YEAR Consortium. PADI4 genotype is not associated with rheumatoid arthritis in a large UK Caucasian population. Ann Rheum Dis 2010;69:666-70.

25. Emery $\mathbf{P}$, Durez P, Dougados $\mathrm{M}$, et al. Impact of T-cell costimulation modulation in patients with undifferentiated inflammatory arthritis or very early rheumatoid arthritis: a clinical and imaging study of abatacept (the ADJUST trial). Ann Rheum Dis 2010;69:510-16.

26. Bennett AN, Rehman A, Hensor EM, et al. The fatty Romanus lesion: a noninflammatory spinal MRI lesion specific for axial spondyloarthropathy. Ann Rheum Dis 2010;69:891-4.

27. Nam JL, Winthrop KL, van Vollenhoven RF, et al. Current evidence for the management of rheumatoid arthritis with biological disease-modifying antirheumatic drugs: a systematic literature review informing the EULAR recommendations for the management of RA. Ann Rheum Dis 2010;69:976-86.

28. Smolen JS, Landewé R, Breedveld FC, et al. EULAR recommendations for the management of rheumatoid arthritis with synthetic and biological disease-modifying antirheumatic drugs. Ann Rheum Dis 2010;69:964-75.

29. Tan RJ, Gibbons LJ, Potter C, et al.; BRAGGSS. Investigation of rheumatoid arthritis susceptibility genes identifies association of AFF3 and CD226 variants with response to anti-tumour necrosis factor treatment. Ann Rheum Dis 2010;69:1029-35.

30. Robinson JI, Barrett JH, Taylor JC, et al.; YEAR Consortium; BRAGGSS. Dissection of the FCGR3A association with RA: increased association in men and with autoantibody positive disease. Ann Rheum Dis 2010;69:1054-7.

31. Cohen SB, Keystone E, Genovese MC, et al. Continued inhibition of structural damage over 2 years in patients with rheumatoid arthritis treated with rituximab in combination with methotrexate. Ann Rheum Dis 2010;69:1158-61.

32. Haugeberg G, Bennett AN, McGonagle D, et al. Bone loss in very early inflammatory back pain in undifferentiated spondyloarthropathy: a 1-year observational study. Ann Rheum Dis 2010;69:1364-6.

33. Schoels M, Aletaha D, Smolen JS, et al. Follow-up standards and treatment targets in rheumatoid arthritis: results of a questionnaire at the EULAR 2008. Ann Rheum Dis 2010;69:575-8

34. Eyre S, Flynn E, Martin P, et al. No evidence for association of the KLF12 gene with rheumatoid arthritis in a large UK cohort. Ann Rheum Dis 2010;69:1407-8.

35. Eyre S, Hinks A, Flynn E, et al. Confirmation of association of the REL locus with rheumatoid arthritis susceptibility in the UK population. Ann Rheum Dis 2010;69:1572-3

36. Orozco G, Eyre S, Hinks A, et al.; Wellcome Trust Case Control consortium YEAR Consortium. Association of CD40 with rheumatoid arthritis confirmed in a large UK case-control study. Ann Rheum Dis 2010;69:813-16.

37. Emery $\mathbf{P}$, Durez P, Dougados $M$, et al. Impact of T-cell costimulation modulation in patients with undifferentiated inflammatory arthritis or very early rheumatoid arthritis: a clinical and imaging study of abatacept (the ADJUST trial). Ann Rheum Dis 2010;69:510-16

38. Saleem B, Keen $\mathrm{H}$, Goeb V, et al. Patients with RA in remission on TNF blockers: when and in whom can TNF blocker therapy be stopped? Ann Rheum Dis 2010;69:1636-42.

39. Barkham N, Coates LC, Keen H, et al. Double-blind placebo-controlled trial of etanercept in the prevention of work disability in ankylosing spondylitis. Ann Rheum Dis 2010;69:1926-8.

40. Emery P, Deodhar A, Rigby WF, et al. Efficacy and safety of different doses and retreatment of rituximab: a randomised, placebo-controlled trial in patients who are biological naive with active rheumatoid arthritis and an inadequate response to methotrexate (Study Evaluating Rituximab's Efficacy in MTX iNadequate rEsponders (SERENE)). Ann Rheum Dis 2010;69:1629-35.

41. Dixon WG, Hyrich KL, Watson KD, et al.; BSRBR Control Centre Consortium; British Society for Rheumatology Biologics Register. Influence of anti-TNF therapy on mortality in patients with rheumatoid arthritis-associated interstitial lung disease: results from the British Society for Rheumatology Biologics Register. Ann Rheum Dis 2010;69:1086-91. 